\title{
Determination of Phenolic Compounds in wines
}

\author{
Charalampos Proestos ${ }^{\mathrm{a},},{ }^{*}$, Athanasios Bakogiannis ${ }^{\mathrm{b}}$, and Michael Komaitis ${ }^{\mathrm{b}}$ \\ ${ }^{a}$ Food Chemistry Laboratory, Department of Chemistry, National and Kapodistrian University of Athens, \\ Panepistimioupolis Zografou, 15771 Athens, Greece \\ ${ }^{\mathrm{b}}$ Laboratory of Food Chemistry, Department of Food Science and Technology, Agricultural University of \\ Athens, Iera Odos 75, 11855 Athens, Greece \\ *harpo@chem.uoa.gr \\ TEL: $+30-210-727-4160$ \\ FAX: +30-210-727-4476
}

Received: 5 May 2011; Published online: 18 April 2012

\begin{abstract}
Wine contains natural antioxidants such as phenolic compounds also known as bioactive compounds. Samples of commercially available Greek wines were analyzed in order to determine this phenolic content. For the analysis, Reversed Phase-High Performance Liquid Chromatography (RP-HPLC) coupled with a multiwavelength Ultraviolet/visible (UV/vis) detector was used. The most abundant phenolic substances detected were $(+)$-catechin $\left(13.5-72.4 \mathrm{mg} \mathrm{L}^{-1}\right)$, gallic acid $\left(0.40-99.47 \mathrm{mg} \mathrm{L}^{-1}\right)$ and caffeic acid (0.87-33.48 $\left.\mathrm{mg} \mathrm{L}^{-1}\right)$. The principal component analysis (PCA) technique was used to study differentiation among wines according to their theproduction area. Red wines contained more phenolic substances than white ones. Differences of the phenolic composition in wines of the same cultivar were investigated too.
\end{abstract}

Keywords: Greek wines; phenolic compounds; RP-HPLC; PCA analysis

\section{Introduction}

Polyphenols are secondary metabolites naturally present in wine grapes and/or produced during the wine making process. They are responsible for the colour, flavour, astringency and hardness of wines as well as for their antioxidant properties (Makris, Psarra, Kallithraka, \& Kefalas, 2003; Seruga, Novak, \& Jakobek, 2011; Kallithraka, Kim, Tsakiris, Paraskevopoulos, \& Soleas, 2011). The latter is associated with biological effects, in particular prevention of cancer, cardiovascular disease and other degenerative diseases (Fernandez-Mar, Mateos, GarciaParrilla, Puertas, \& Cantos-Villar, 2012). Consequently, polyphenols have received considerable attention. Additionally, phenolics act as: a) metal chelators (Hider, Liu, \& Khodr, 2001), b) antimutagens and anticarcinogens (Ferguson, 2001; He, Sun, \& Pan, 2008), c) antimicrobial agents (Nychas, Tassou, \& Skandamis, 2003; Rodriguez Vaquero, Alberto, \& Manca de Nadra, 2007) and d) clarifying agents (Ferreira, PicarraPereira, Monteiro, Loureiro, \& Teixeira, 2001). They are formed from the fruit and vine stems, by the yeast metabolism and/or other raw materials from vegetal origin. In addition, phenolics serve as important oxygen reservoirs and substrates for browning reactions. Phenolic compounds are also significant in white wines, where they occur at much lower concentrations. Aging in wood barrels results in a temporary increase of the phenolic content. They are possibly extracted from wood barrel. Cask wood acts as an extraction support for various phenolic compounds (Alañon, Castro-Vazquez, Diaz-Maroto, 
Gordon, \& Perez-Coello, 2011). The main aim of this study was to determine phenolic compounds in red and white wines, as well as to study differentiation among wines according to their production area by using principal component analysis (PCA) technique. Also the differences of the phenolic composition in wines of the same cultivar were studied.

\section{Experimental}

\subsection{Standards and solvents}

Gallic acid, p-coumaric acid, ferulic acid, syringic acid, (+)-catechin and quercetin were purchased from Sigma-Aldrich (Steinheim, Germany). Caffeic acid was obtained from Merck (Darmstadt, Germany) and (-)-Epicatechin was from Fluka AG (Buchs, Switzerland). Hydroxytyrosol was a kind donation from the National Agricultural Research Foundation (N.AG.RE.F, Greece). Stock solutions of all the standards were prepared (1000 $\left.\mathrm{mg} \mathrm{L}^{-1}\right)$ in water-acetic acid-acetonitrile (62:6:32 $\mathrm{v} / \mathrm{v} / \mathrm{v})$. Working standards were made by diluting the stock solutions in the same solvent. Both stock and working standards were stored at $-18^{\circ} \mathrm{C}$ until needed.

\section{$2.2 \quad$ Wine samples}

A total of 24 wine samples were analyzed. Most of them were commercial wines. A list of all wines analyzed in this study is presented in Table 1 . The HPLC analysis was performed without any particular treatment except filtration through membrane filters $0.45 \mathrm{\mu m}$ (Millex-HV). Each determination was carried out in triplicate.

\subsection{HPLC Analysis}

The HPLC apparatus used for the analysis consisted of a ternary gradient unit (Jasco CG-158002), a pump (Jasco PU-980), a multiwavelength detector UV/vis (Jasco MD-910) programmed to take data from 250-400 $\mathrm{nm}$ with a $4 \mathrm{~nm}$ resolution, a data processing system (Jasco DPL910/V), a reversed phase column Nova PakB, C18 with a packing $4 \mu \mathrm{m}$ (Waters, USA) protected by a guard column Nova Pakß, C18, and finally, a rheodyne injection system (model $7725 \mathrm{i}$ ) with a loop of $20 \mu \mathrm{L}$. Nova Pak@ stationary phase, which was used in this study to separate phenolic acids and flavonoids of wines, produced satisfactory results. Gradient elution of three solvents was used: Solvent A consisted of: acetic-water $(1: 99 \mathrm{v} / \mathrm{v})$, solvent $\mathrm{B}$ : acetic-water $(6: 94 \mathrm{v} / \mathrm{v})$ and solvent $\mathrm{C}$ : acetic-acetonitrilewater $(5: 30: 65 \mathrm{v} / \mathrm{v} / \mathrm{v})$. The gradient program used was based on that of (Garcia-Parrilla, Heredia, \& Troncoso, 1999): 100\% A initially, 100\% B 0-15 min, $100 \%$ B 15-30 min, 90\% B/10\%C 3050 min, $80 \%$ B/20\% C 50-60 min, $70 \%$ B/30\% C 60-80 min, 100\% C 80-120 min, 100\% C 120-140 min. The flow rate was $0.5 \mathrm{~mL} \mathrm{~min}^{-1}$ and the temperature was set at $22.5^{\circ} \mathrm{C}$. The monitoring wavelength was $278 \mathrm{~nm}$. The identification of each compound was based on a combination of retention time and spectral matching. Quantification was done via a calibration with standards with LOD 0.06 ppm and LOQ 0.18 ppm.

\subsection{Statistics and data presentation}

Data are reported as mean and standard deviation. The \% relative standard deviation (RSD) was also determined. The mean values obtained in the different samples studied were compared by MANOVA (Multi-Factor Analysis of Variance). PCA was employed by using the software Statistica v6.0 SR, to distinguish wines based on their phenolic composition. PCA permitted us to achieve a reduction of dimensionality, exploring the relationships between objects, estimating the correlation structure of the variables and investigating how many components were necessary to explain the greater part of variance with a minimum loss of information. When PCA is performed on autoscaled matrix data the principal component loadings are eigenvectors of the correlation matrix (Wold, Esbensen, \& Geladi, 1987).

\section{Results and Discussion}

The present method is simple, easy to use and effective enough for the identification and quantification of major phenolic compounds in aro- 
Table 1: List of the analyzed wine samples

\begin{tabular}{|c|c|c|c|c|}
\hline $\begin{array}{l}\text { Sample } \\
\text { no. }\end{array}$ & Label & Color & Cultivar(s) & Location \\
\hline 1 & Kokkineli, 1999 & Red & Various & Central Greece \\
\hline 2 & $\begin{array}{c}\text { Conv. culture, } 7 \\
\text { months in oak } \\
\text { barrel, } 2000\end{array}$ & Red & Agiorgitiko & Peloponnese \\
\hline 3 & $\begin{array}{c}\text { Organic culture, } \\
2000\end{array}$ & Red & Agiorgitiko & Peloponnese \\
\hline 4 & $\begin{array}{l}\text { Strofilia, Org. } \\
\text { Culture, } 1999\end{array}$ & White & Roditis & Peloponnese \\
\hline 5 & Wine A, 2000 & Red & Various & Kriti \\
\hline 6 & Wine B, 1998 & White & Various & Central Greece \\
\hline 7 & $\begin{array}{l}\text { Kritikos topikos } \\
\text { oinos, Mpoutaris } \\
1999\end{array}$ & White & Vilana & Kriti \\
\hline 8 & $\begin{array}{c}\text { Strofilia, 1997, } \\
\text { vine-harvest }\end{array}$ & Red & Various & Attiki \\
\hline 9 & $\begin{array}{c}\text { Strofilia, } \\
\text { convetional } \\
\text { culture, } 2000\end{array}$ & White & Savvatiano & Central Greece \\
\hline 10 & $\begin{array}{l}\text { Strofilia, organic } \\
\text { culture, } 2000\end{array}$ & White & Savvatiano & Central Greece \\
\hline 11 & $\begin{array}{l}\text { Strofilia, organic } \\
\text { culture, } 2000\end{array}$ & White & Chardonnay & Central Greece \\
\hline 12 & $\begin{array}{l}\text { Strofilia, organic } \\
\text { culture, } 2000\end{array}$ & Red & Cabernet Sauvignon & Attica \\
\hline 13 & Agiampelos, 2000 & Red & Various & Peloponnese \\
\hline 14 & Wine Nama 2000 & Red & Various & Santorini \\
\hline 15 & $\begin{array}{c}\text { Wine of Patras, } \\
1999\end{array}$ & Red & Mavrodaphni & Peloponnese \\
\hline 16 & $\begin{array}{c}\text { Kokkineli, } \\
\text { Kourtakis } 2000\end{array}$ & Red & Various & Attica \\
\hline 17 & $\begin{array}{c}\text { Red wine of } \\
\text { Nemeas } 2001\end{array}$ & Red & Various & Attica \\
\hline 18 & Wine D, 2000 & Red & Agiorgitiko+ Cabernet Sauvignon & Peloponnese \\
\hline 19 & Wine E 1999 & White & Various & Attica \\
\hline 20 & Makedonikos, 1999 & Red & Various & Macedonia \\
\hline 21 & Wine F, 2000 & Red & Various & Attica \\
\hline 22 & Savvatiano, 2000 & White & Savvatiano & Central Greece \\
\hline 23 & Cellar 2001 & White & Fileri+Roditis+ Chardonnay & Peloponnese \\
\hline 24 & Agiampelos, 2000 & White & Various & Peloponnese \\
\hline
\end{tabular}


$36 \mid$ Proestos et al.

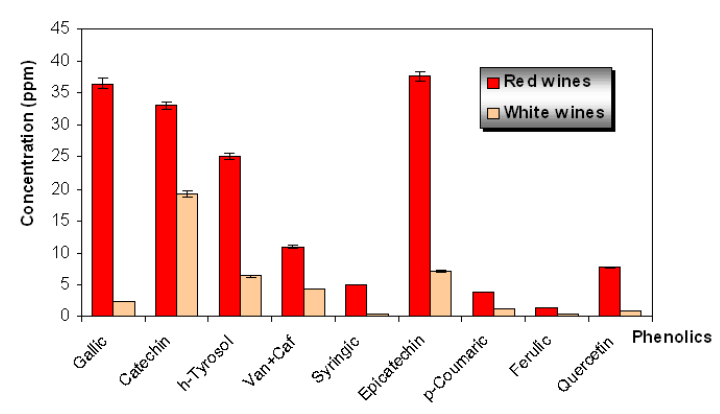

Figure 1: Comparison of phenolic concentration in red and white wines.

matic plants. A similar technique or previous treatment of the sample, in other words, simple filtration has been reported by other authors, for the analysis of major phenolic compounds (Gambelli \& Santaroni, 2004; Rodriguez-Bernaldo de Quiros, Lage-Yusty, \& Lopez-Hernandez, 2009). The amount of phenolic compounds detected in the samples is shown in Table 2. Results are expressed in $\mathrm{mg} \mathrm{L}^{-1}$ wine sample \pm standard deviation. Another phenolic compound which was detected in most of the samples was hydroxytyrosol which ranged from 0.22 to $54.27 \mathrm{mg} \mathrm{L}^{-1}$. In the making of red wine, fermentation only takes place after the maceration phase on the whole must that is obtained after crushing, and pressing. Maceration enables the extraction of constituents present in the skins and seeds into the fermenting must, including not only polyphenols and red pigments, but also tannins, volatile compounds and aroma precursors, and plant cell wall polysaccharides. Shi, Yu, Pohorly, and Kakuda (2003) showed that the phenolic compounds commonly found in white grapes (seeds removed) are esters of hydroxycinnamic acid, catechins, and procyanidins. Phenolics in red grapes contain mainly hydroxycinnamic acid-tartaric acid esters, procyanidins, flavonol glycosides, and anthocyanins. Phenolic substances were present in higher amounts in red wines than in the white ones, probably due to the prolonged contact period of the pomace with skin. This hypothesis is supported by the comparison of the mean concentration of each phenolic substance present in the red and white wines respectively as shown in Figure 1.

\subsection{Differences of the phenolic composition in wines of the same cultivar}

Samples no 9, 10 and 22 were wines of the same cultivar (Savvatiano). For these samples, no significant differences were observed although they come from different farms. Each analysis was performed in triplicate. Statistical analysis (t-test, Statistica, 1991) showed that the differences between the wines were not significant $(p>0.05)$. The similarities in the phenolic composition of these three wines are shown in Figure 2. Sample no. 10 was a conventional wine and sample no. 11 was an organic culture. There were no discrete differences between the two wines that could distinguish them. Although the number of samples analyzed was very small and no conclusion can be drawn, it is believed that the concentration of trans-resveratrol (Tinttunen \& Lehtonen, 2001) may offer a good criterion for distinguishing normal from organic wine.

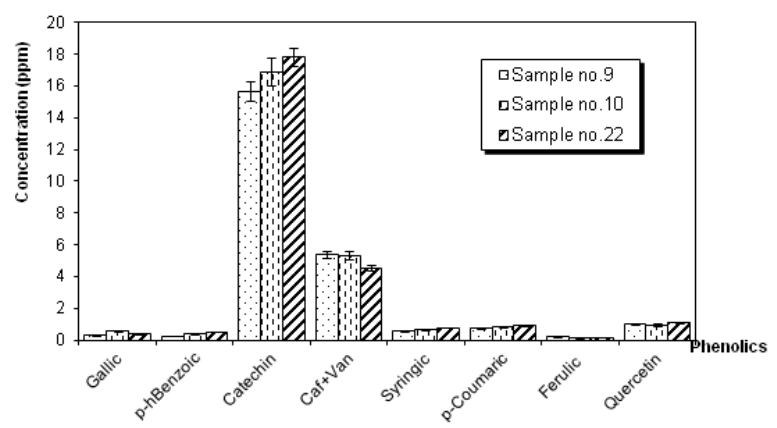

Figure 2: Comparison of the levels of phenolics in wines of the same cultivar (Savvatiano).

\subsection{Principal component analysis (PCA) for phenolic compounds in both red and white wines}

The phenolic content and composition of wine is greatly influenced by four agroecological factors: the cultivar, the year of production (i.e., 
Phenolic Compounds in Wines $\mid 37$

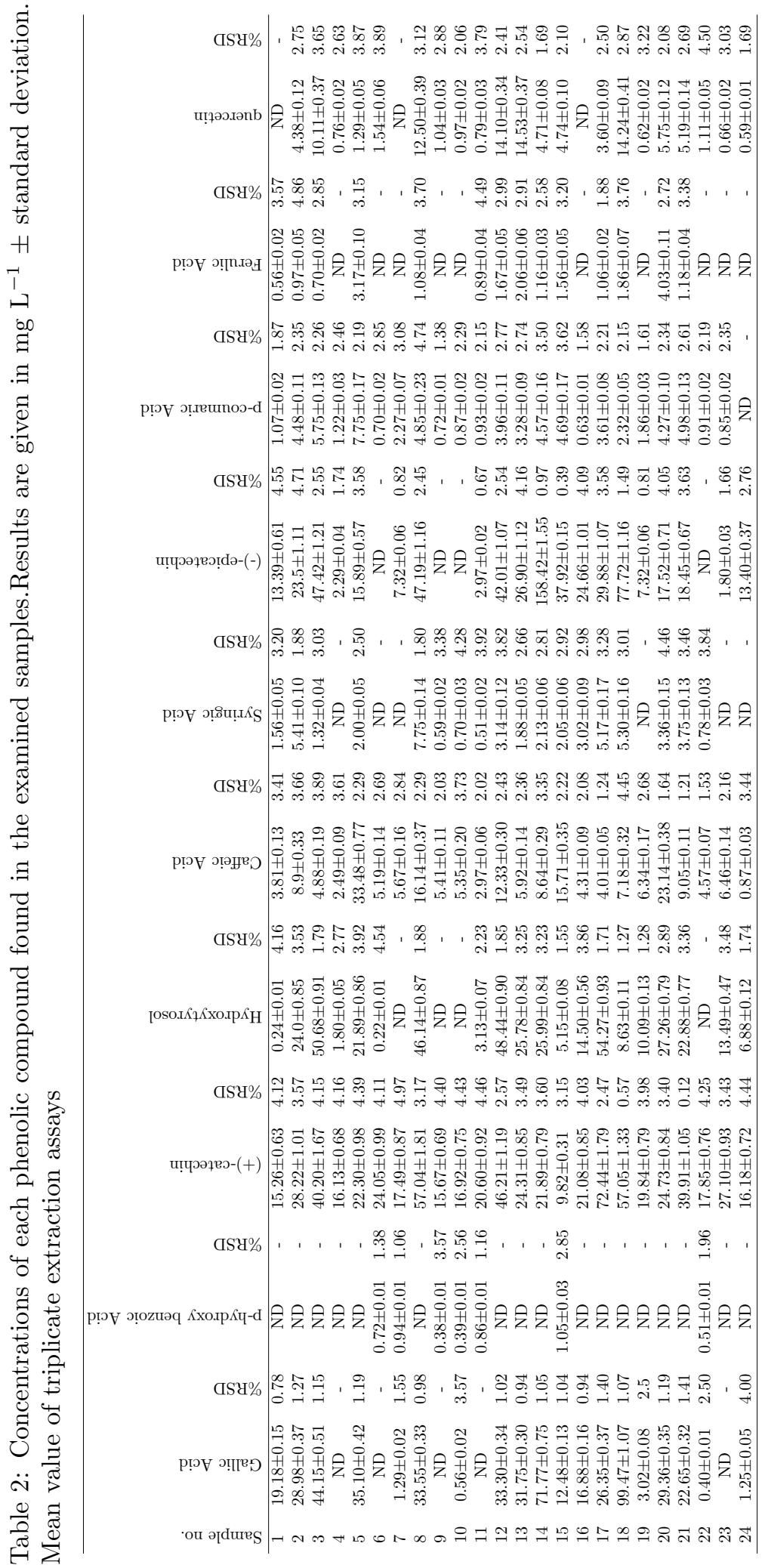

IJFS | April 2012 | Volume 1 | pages 33-41 
the climatic condition from year to year), the site of production (the effect of geographic origin of grapes, soil chemistry, and fertilization), and the degree of maturation (Shi et al., 2003). Since the polyphenolic content varies from one area to another, it has been used in an attempt to distinguish the wines according to production area, as well as differences between red and white wines. As regards white wines, only two principal components were used whose eigenvalues were greater than one (eigenvalue-greater-thanone rule in the case of standardized data). In the case of the red wines, three principal components were used. The principal components scores for both the red and white wines (Figure 3) showed that the wines from central Greece to a greater extent and those from Attica to a lesser extent, were located inside specific regions of factors 1 and 2 and thus, there was a relationship between the compounds quantified and the aforementioned wines. Factor 1 was mainly dependent on (+)-catechin, (-)-epicatechin, caffeic acid and quercetin whereas factor 2 depended on gallic and p-coumaric acids. It was shown clearly that only for the wines coming from the Peloponnese was a relationship between the phenolic substances used and their origin. It was found that all the wines from Peloponnese are concentrated all together (Figures 4, 5 and 6). Factor 1 mainly depended on (+)-catechin and quercetin, factor 2 depended on the hydroxycinnamic acids used and finally, factor 3 was dependent on (-)-epicatechin. A similar PCA analysis was used to determine the most important differences in phenolic content among wines from the Canary Islands (Spain) according to different categories such as island, zone and denomination of origin (Rodriguez-Delgado, GonzalezHernandez, Conde-Gonzalez, \& Perez-Trujillo, 2002). In general, red wines from the Canary Islands had a polyphenol content in the lower part of the range considered normal. The exception was quercetin, with a mean content higher than in other wines, which may be a peculiarity of these particular wines.

\section{Conclusion}

Phenolic compounds constitute a diverse group of secondary metabolites which are present in both grapes and wines. The results of this study have shown that red wines contained higher amounts of phenolic substances than white ones. The most abundant phenolic substances detected in the wines were $(+)$-catechin (13.5-72.4 mg $\left.\mathrm{L}^{-1}\right)$, gallic acid $\left(0.40-99.47 \mathrm{mg} \mathrm{L}^{-1}\right)$ and caffeic acid (0.87-33.48 $\left.\mathrm{mg} \mathrm{L}^{-1}\right)$. Differences in the phenolic composition in wines of the same cultivar were not found to be significant. All the samples were injected directly into the HPLC system in order to avoid possible changes. Hence, quantification was more reliable as there are no losses due to sample treatment. PCA statistical method was employed to find out if it is possible to distinguish wines based on their phenolic composition. Only wines of Central Greece were located inside specific regions of the factors 1 and 2. Factor 1 was mainly dependent on (+)-catechin, ()-epicatechin, caffeic acid and quercetin whereas factor 2 depended on gallic and p-coumaric acids. Also wines with Peloponnese origin were the only ones which could be estimated through their phenolic content. In all the three plots (Fig. 6-8) all wines from Peloponnese were close together. Factor 1 mainly depended on (+)-catechin and quercetin, factor 2 depended on the hydroxycinnamic acids used and finally, factor 3 was dependent on (-)-epicatechin. Of course if a larger number of wines from different regions of Greece were analyzed, then it would be easier to create a reliable method for estimating the origin of wines.

\section{Acknowledgements}

The authors would like to thank Dr. P. Lanaridis (N.AG.RE.F) for providing the standards used in the research.

\section{References}

Alañon, M. E., Castro-Vazquez, L., Diaz-Maroto, M. C., Gordon, M. H., \& Perez-Coello, M. 
Phenolic Compounds in Wines $\mid 39$

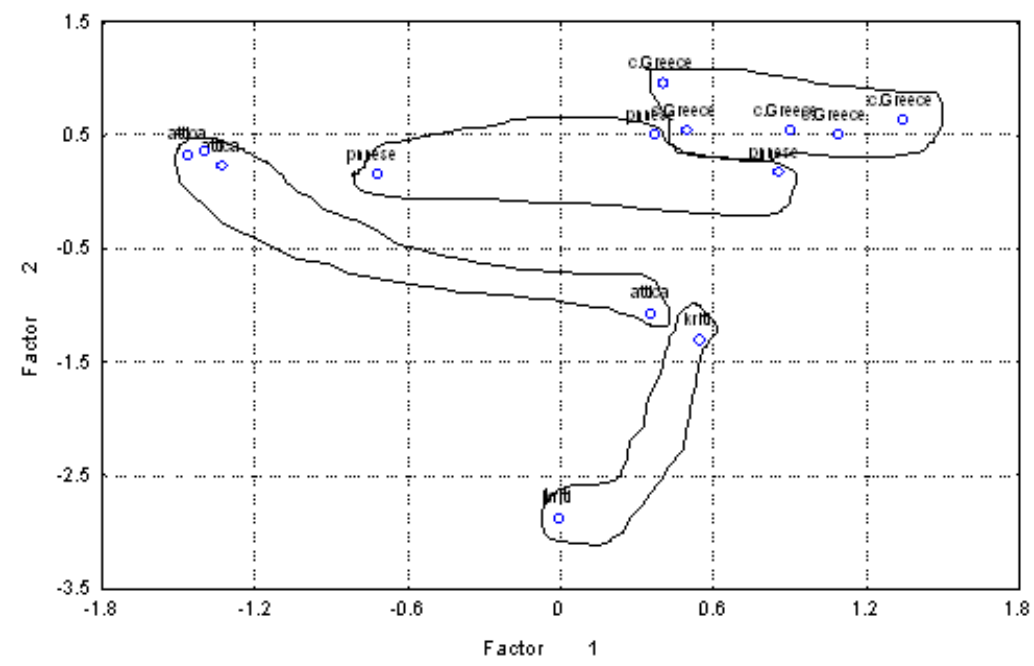

Figure 3: Plot of the two principal components scores issued from PCA for white wines (attica, kriti, pnnese $=$ peloponnese and $c$. Greece $=$ central Greece). Factor 1 is mainly dependent on $(+)$-catechin, (-)epicatechin, caffeic acid and quercetin whereas factor 2 depends on gallic and p-coumaric acid.

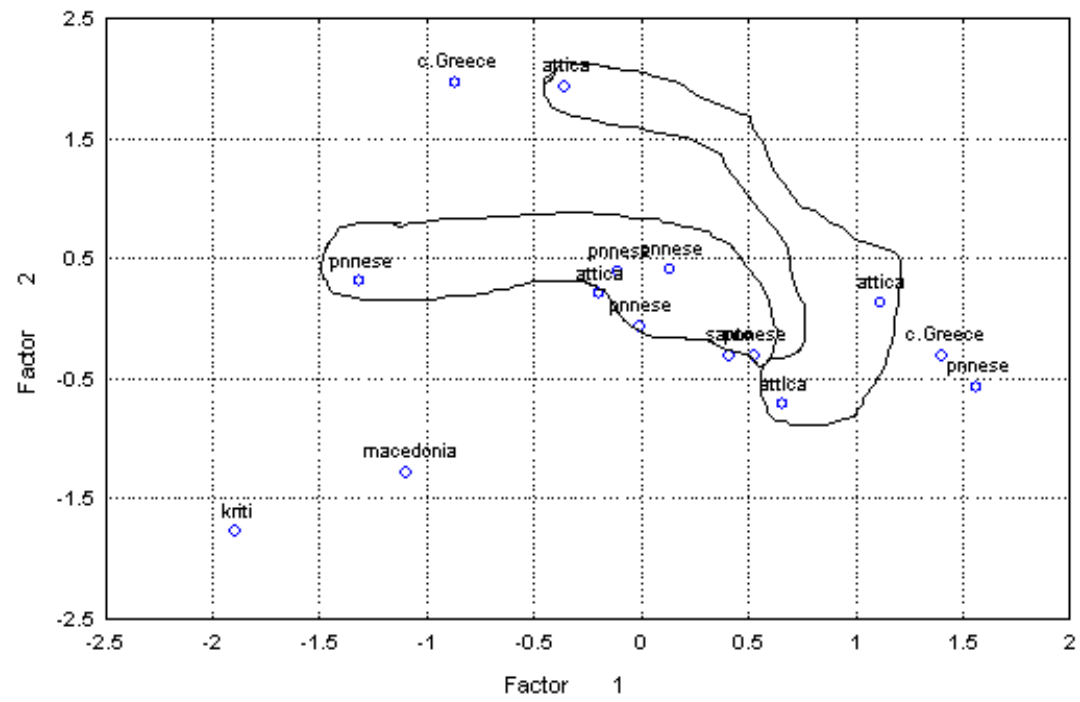

Figure 4: Plot of the factor 1 vs. factor 2 for the red wines (santo=the greek island Santorini). Factor 1 mainly depends on $(+)$-catechin and quercetin, factor 2 depends on the hydroxycinnamic acids used and finally, factor 3 is dependent on (-)-epicatechin. 
$40 \mid$ Proestos et al.

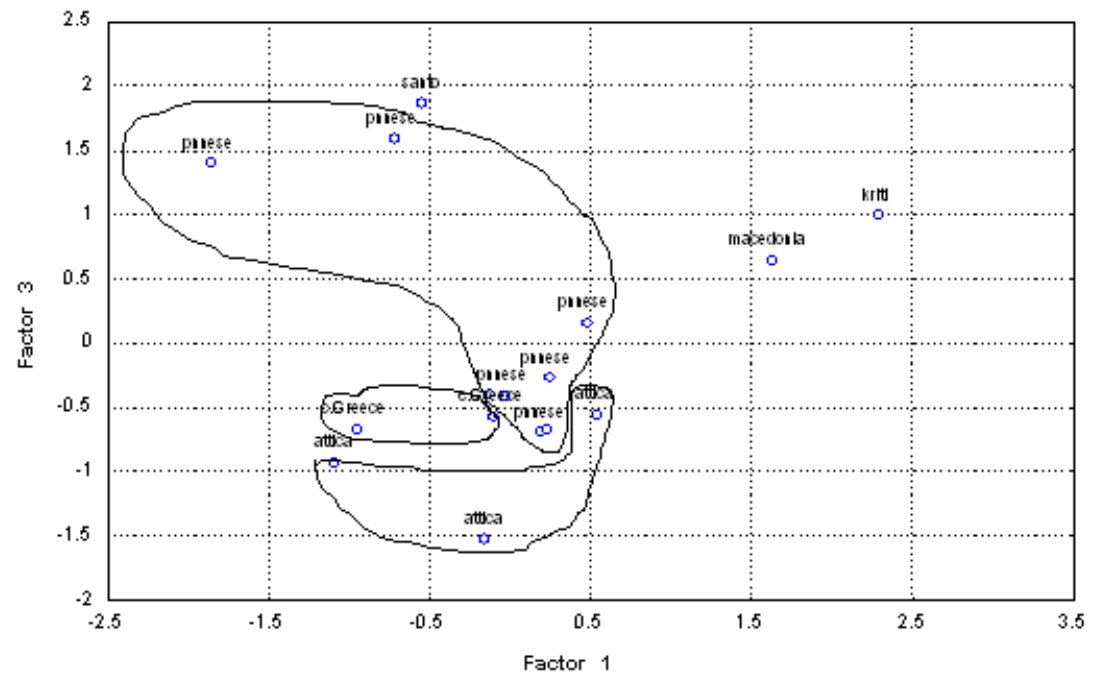

Figure 5: Plot of the factor 1 vs. factor 3 for the red wines. Factor 1 mainly depends on (+)-catechin and quercetin, factor 2 depends on the hydroxycinnamic acids used and finally, factor 3 is dependent on (-)-epicatechin.

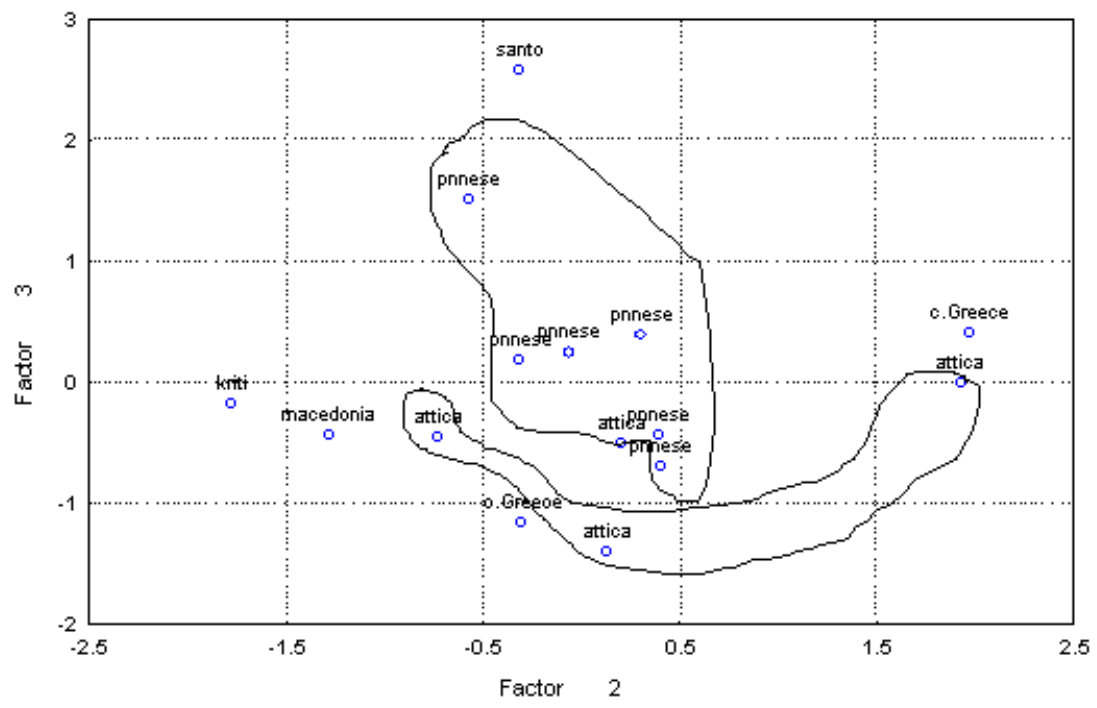

Figure 6: Plot of the factor 2 vs. factor 3 for the red wines. Factor 1 mainly depends on (+)-catechin and quercetin, factor 2 depends on the hydroxycinnamic acids used and finally, factor 3 is dependent on (-) epicatechin. 
S. (2011). A study of the antioxidant capacity of oak wood used in wine ageing and the correlation with polyphenol composition. Food Chemistry, 128(4), 997-1002. doi:10. 1016/j.foodchem.2011.04.005

Ferguson, L. R. (2001). Role of plant polyphenols in genomic stability. Mutation Research/Fundamental and Molecular Mechanisms of Mutagenesis, 475, 89-111.

Fernandez-Mar, M. I., Mateos, R., GarciaParrilla, M. C., Puertas, B., \& CantosVillar, E. (2012). Bioactive compounds in wine: resveratrol, hydroxytyrosol and melatonin: a review. Food Chemistry, 130(4), 797-813. doi:10.1016/j.foodchem.2011.08. 023

Ferreira, R., Picarra-Pereira, M., Monteiro, S, Loureiro, V., \& Teixeira, A. (2001). The wine proteins. Trends In Food Science 8 Technology, 12(7), 230-239. doi:10.1016/ S0924-2244(01)00080-2

Gambelli, L, \& Santaroni, G. (2004). Polyphenols content in some italian red wines of different geographical origins. Journal Of Food Composition And Analysis, 17(5), 613-618. doi:10.1016/j.jfca.2003.09.010

Garcia-Parrilla, M., Heredia, F., \& Troncoso, A. (1999). Sherry wine vinegars: phenolic composition changes during aging. Food Research International, 32(6), 433-440. doi:10.1016/S0963-9969(99)00105-2

He, S., Sun, C., \& Pan, Y. (2008). Red wine polyphenols for cancer prevention. International Journal Of Molecular Sciences, 9(5), 842-853. doi:10.3390/ijms9050842

Hider, R., Liu, Z., \& Khodr, H. (2001). Metal chelation of polyphenols. Methods in Enzymology. Flavonoids and other Polyphenols, 335, 190-203.

Kallithraka, S., Kim, D., Tsakiris, A., Paraskevopoulos, I., \& Soleas, G. (2011). Sensory assessment and chemical measurement of astringency of greek wines: correlations with analytical polyphenolic composition. Food Chemistry, 126(4), 1953-1958. doi:10.1016/j.foodchem.2010.12.045

Makris, D., Psarra, E, Kallithraka, S, \& Kefalas, P. (2003). The effect of polyphenolic composition as related to antioxidant capacity in white wines. Food Research Interna- tional, 36(8), 805-814. doi:10.1016/S09639969(03)00075-9

Nychas, G.-J., Tassou, C., \& Skandamis, P. (2003). Natural antimicrobials for the minimal processing of foods. In S. Roller (Ed.), (Chap. Making the most of herbs, spices and their active components. pp. 176-200). Cambridge: Woodhead Publishing.

Rodriguez-Bernaldo de Quiros, A., Lage-Yusty, M. A., \& Lopez-Hernandez, J. (2009). Hplc-analysis of polyphenolic compounds in spanish white wines and determination of their antioxidant activity by radical scavenging assay. Food Research International, 42(8), 1018-1022. doi:10.1016/j. foodres.2009.04.009

Rodriguez-Delgado, M., Gonzalez-Hernandez, G, Conde-Gonzalez, J., \& Perez-Trujillo, J. (2002). Principal component analysis of the polyphenol content in young red wines. Food Chemistry, 78(4), 523-532. doi:10. 1016/S0308-8146(02)00206-6

Rodriguez Vaquero, M. J., Alberto, M. R., \& Manca de Nadra, M. C. (2007). Antibacterial effect of phenolic compounds from different wines. Food Control, 18(2), 93-101. doi:10.1016/j.foodcont.2005.08.010

Seruga, M., Novak, I., \& Jakobek, L. (2011). Determination of polyphenols content and antioxidant activity of some red wines by differential pulse voltammetry, hplc and spectrophotometric methods. Food Chemistry, 124(3), 1208-1216. doi:10.1016/j . foodchem.2010.07.047

Shi, J., Yu, J., Pohorly, J., \& Kakuda, Y. (2003). Polyphenolics in grape seeds-biochemistry and functionality. Journal of Medicinal Food, 6, 291-299.

Tinttunen, S, \& Lehtonen, P. (2001). Distinguishing organic wines from normal wines on the basis of concentrations of phenolic compounds and spectral data. European Food Research And Technology, 212(3), 390-394. doi:10.1007/s002170000265

Wold, S, Esbensen, K, \& Geladi, P. (1987). Principal component analysis. Chemometrics And Intelligent Laboratory Systems, 2(13), 37-52. doi:10 . $1016 / 0169-7439(87)$ 80084-9 